\title{
Letter-to-the-Author
}

\section{Paragonimiasis in Brazil}

Felipe Francisco Tuon ${ }^{1}$, Valdir Sabbaga Amato ${ }^{2}$ and Vicente Amato Neto ${ }^{3}$

${ }^{1}$ Department of Infectious and Parasitic Diseases, University of Sao Paulo, Medical School; ${ }^{2}$ Infectious and Parasitic Diseases Clinic, Hospital das Clínicas, Medical School, University of Sao Paulo; ${ }^{3}$ Laboratory of Medical Investigation and Parasitology (LIM 46), University of Sao Paulo, Medical School; São Paulo, SP, Brazil

Dear Dr. Lemos,

The paragonimiasis has a wide distribution in the world, but occurs in areas where there is the consumption of hosts contaminated by metacercaria of Paragonimus, as raw or slightly cooked lobsters and crabs. Human cases occur mainly in Southeast Asia and Japan; Taiwan, Thailand, India, China and Korea are the countries with endemic levels although many cases were described in the north Africa. The cooking of these countries encourages the spread and maintenance of the disease.

In the Americas, there are several cases in South American countries on the Pacific coast, such as Peru and Ecuador [1]. In the United States, although most cases are from patients who have traveled or lived in endemic areas in the East, a few cases are indigenous, described in regions where a Paragonimus sp. different from that found in the East occurs in the environment in mammalian hosts. Some cases are commonly described in USA due to the habit of eating raw contaminated food in some provinces.

Ecuador is considered a country with endemic levels of paragonimiasis. In 1850, it was reported the presence of a kind of Paragonimus in an otter in the state of Mato Grosso, Brazil. However, several studies in this region failed to demonstrate other hosts with the parasite; this case was never confirmed [2,3].

Regarding to intermediate hosts, there are several species of shellfish that can host the parasite. In Brazil, there is potential for the existence of paragonimiasis in humans after the discovery of a large number of Thiara tuberculata in Santos (state of Sao Paulo) and others in the basin of the high Parana [4]. If introduced in these regions, there may be a risk of disease dissemination in the local population due to consumption of freshwater shellfish contaminated with the parasite.

The description of the first human case in Brazil, related by you and collegues, published in this Journal (Braz J Infect Dis 2007(1):153-156), should be faced as the tip of the iceberg and a seroepidemiological evaluation might be considered [5]. The paragonimiasis is not considered a neglected tropical disease, but several characteristics of this parasite fulfill previous criteria used to define these entities.

\section{References}

1. Guevara A., Vieira J.C., Araujo E., et al. Antibody isotypes, including IgG subclasses, in Ecuadorian patients with pulmonary paragonimiasis. Mem Inst Oswaldo Cruz 1995;90:497-502.

2. Meira J.A., Correa M.O. Paragonimus westermani in Brazil. Notes on an old study. Rev Soc Bras Med Trop 1986;19:193-4.

3. Voelker J., Muller G., Prata A. What is Paragonimus rudis (Diesing, 1850)? Report on a field study in Mato Grosso, Brazil. Mem Inst Oswaldo Cruz 1981;76:409-14.

4. Vaz J.F., Teles H.M., Correa M.A., Leite S.P. Occurrence in Brazil of Thiara (Melanoides) tuberculata (O.F. Muller, 1774) (Gastropoda, Prosobranchia), the 1st intermediate host of Clonorchis sinensis (Cobbold, 1875) (Trematoda, Plathyhelmintes). Rev Saude Publica 1986;20:318-22.

5. Lemos A.C., Coelho J.C., Matos E.D., et al. Paragonimiasis: first case reported in Brazil. Braz J Infect Dis 2007;11:153-6.

Received on 12 November 2007; revised 31 January 2008.

Address for correspondence: Dr. Felipe Francisco Tuon. Department of Infectious Diseases, University of Sao Paulo, Medical School, Sao Paulo, Brazil. Avenida Dr. Enéas de Carvalho Aguiar, 470. Cerqueira César. Zip code: 05403-000. São Paulo, SP, Brazil. E-mail: ffbt@pop.com.br. Telephone: 551130696530 . Fax: 551130697508.

The authors are not part of any association or commercial relationship that might represent conflicts of interest in the writing of this study (e.g., pharmaceutical stock ownership, consultancy, advisory board membership, relevant patents, or research funding). This article has no financial support. 